medRxiv preprint doi: https://doi.org/10.1101/2022.01.06.22268809; this version posted January 6, 2022. The copyright holder for this preprint (which was not certified by peer review) is the author/funder, who has granted medRxiv a license to display the preprint in perpetuity.

It is made available under a CC-BY-NC-ND 4.0 International license .

\title{
Mental health assessment of Israeli adolescents before and during the COVID-19 pandemic
}

Yonatan Bilu ${ }^{1},{ }^{\dagger}$, Natalie Flaks-Manov ${ }^{1}$, Maytal Bivas-Benita ${ }^{1}$, Pinchas Akiva ${ }^{1}$, Nir Kalkstein ${ }^{1}$, Yoav Yehezkelli ${ }^{1}$, Miri Mizrahi-Reuveni ${ }^{2}$, Anat Aka-Zohar ${ }^{2}$, Shirley Shapiro Ben David ${ }^{2}$, Uri Lerner ${ }^{2}$, Gilad Bodenheimer $^{2}$ and Shira Greenfeld ${ }^{2}$

${ }^{1}$ KI Research Institute, Kfar-Malal, Israel

${ }^{2}$ Maccabi Healthcare Services, Tel-Aviv, Israel

${ }^{\dagger}$ Corresponding author: Yonatan Bilu, KI Research Institute, 11 Hazayit st, Kfar Malal, Israel. Email: yonatan@kinstitute.org.il

\begin{abstract}
The measures used to contain the COVID-19 pandemic caused severe disruption to the lives of children and adolescents, compromising their mental health and wellbeing. In this study we assessed the incidence rates of psychiatric diagnoses and drugs in Israeli adolescents before and during the COVID-19 pandemic. Analysis of health records data of over 200,000 12-17 years old adolescents identified a significant increase in all mental health diagnoses and most psychiatric drugs dispensation during the COVID-19 period compared to a corresponding pre-COVID period. A gender sub-analysis revealed that most of this increase was associated with adolescent girls. Girls exhibited increases of $68 \%$ in depression, $67 \%$ in eating disorders, $42 \%$ in anxiety and 29\% in stress-related diagnoses during the COVID-19 period, which are significantly higher rates than those seen in boys and in the pre-COVID period. Sector sub-analysis showed that the increase was mainly in the general Jewish sector with almost no significant increases in the Arab and ultra-orthodox sectors. Our study highlights the mental health burden of Israeli adolescents during the pandemic and suggests that careful consideration should be given to it while deciding on measures to mitigate the pandemic.
\end{abstract}


medRxiv preprint doi: https://doi.org/10.1101/2022.01.06.22268809; this version posted January 6, 2022. The copyright holder for this preprint (which was not certified by peer review) is the author/funder, who has granted medRxiv a license to display the preprint in perpetuity.

It is made available under a CC-BY-NC-ND 4.0 International license .

\section{Introduction}

The COVID-19 pandemic and the measures taken to control its spread have transformed the lives of adolescents, raising concern regarding their mental health. Although children and adolescents mostly represent a milder course of COVID-19 compared to adults ${ }^{1}$, the measures taken to contain the disease, such as school closures and social isolation, have negatively impacted the mental health and wellbeing of this young population ${ }^{2}$. Current reports have indicated that depression, anxiety and eating disorders have increased significantly during the pandemic and higher prevalence rates were measured in girls ${ }^{3-5}$, increasing gradually with age between the ages of 12 and 17 years (up to their $18^{\text {th }}$ birthday) ${ }^{6}$. As Israel is getting prepared to contain the fifth coronavirus wave, the additional burden on children and adolescents' mental wellbeing should be weighed. In this study we assessed updated incidence of Israeli youth mental illness before and during the COVID-19 pandemic based on electronic health records (EHR).

\section{Methods}

Data in this study originated from Maccabi Health Services (MHS), the second largest Health Maintenance Organization (HMO) in Israel, which includes 2.3 million insured citizens. We performed a retrospective cohort study design of adolescents, 12-17 years old (up to their $18^{\text {th }}$ birthday) between November $1^{\text {st }}, 2016$, and November $1^{\text {st }}, 2021$. The outcomes included four categories of mental health diagnoses: depression (ICD10 F32, F34); anxiety and OCD disorders (ICD10 F41, F42); adjustment and emotional problems and stress-related conditions (ICD10 F43, F93.9; denoted as "stress") and eating disorders (ICD10 F50) and three drug categories of antidepressants (ATC code N06A), anxiolytics (ATC code N05B) and antipsychotics (ATC code N05A) dispensed during those years.

Incidence was computed by considering the cohort of all MHS members 12-17 years old at the beginning of the year, who did not previously receive a diagnosis, or a medication of the type being considered. Then the number of members from this cohort who received such a diagnosis or medication during the year was counted and normalized by the size of the cohort. Relative Risks (RRs) per 1,000 members and 95\% confident intervals (CIs) were computed to measure the changes in mental illness trends between two time periods: pre-COVID (year 2019 vs 2017) and during COVID (year 2021 vs 2019). Since our data extended up to Oct $31^{\text {st }}, 2021$, each analyzed year started on Nov $1^{\text {st }}$ of the previous year and ended on Oct $31^{\text {st }}$. To present the 
medRxiv preprint doi: https://doi.org/10.1101/2022.01.06.22268809; this version posted January 6, 2022. The copyright holder for this preprint (which was not certified by peer review) is the author/funder, who has granted medRxiv a license to display the preprint in perpetuity.

It is made available under a CC-BY-NC-ND 4.0 International license .

results of the RRs and CIs we used forest plots. Statistical analyses were conducted using Python version 3.7.1.

\section{Ethics declarations}

This report is a sub-analysis of a larger research studying the long-term effects of COVID-19 infection. The study was carried out in accordance with relevant guidelines and regulations. The protocol was approved, and informed consent was waived by Maccabi Health Services' institutional review board (MH6-0006-21). The study included retrospective, de-identified data therefore, presented minimal risk and did not adversely affect the rights and welfare of the subjects. All investigators that were involved in the current study performed GCP training for human subjects' studies and had a completion certificate in effect.

\section{Results}

We evaluated the EHR data of 12-17 years old adolescents to assess mental health outcomes before and during the pandemic. The population numbers differed between outcomes as we excluded those with a history of the specific outcome, therefore an average population size was 211,404 in 2017, 218,906 in 2019 and 229,528 in 2021. On average, 51.1\% were male, 80.2\% were general Jews, 12.4\% ultra-orthodox Jews, and 7.5\% were Arabs. Diagnoses and medication incidence rates for mental health increased over time, however the rise was higher during the COVID-19 period than the pre-COVID period (Table 1). For example, the incidence rates of depression increased from 4.0 per 1,000 in 2017 to 4.1 in 2019 and to 5.7 in 2021.

Comparing the incidence in the pre-COVID time periods (Figure 1), we observed a nonsignificant increase in 2019, relative to 2017 of new diagnoses of depression $(\mathrm{RR}=1.04 ; 95 \% \mathrm{CI}$ : 0.94-1.14), anxiety ( $\mathrm{RR}=1.05$; 95\% CI: 0.98-1.13) and eating disorders ( $\mathrm{RR}=1.04$; 95\% CI: 0.93 1.18) and a decrease in new diagnoses related to stress ( $\mathrm{RR}=0.97 ; 95 \% \mathrm{CI}$ : 0.97-1.03), alongside a significant decrease in the incidence of anxiolytics ( $\mathrm{RR}=0.86 ; 95 \% \mathrm{CI}$ : 0.76-0.99) and increase in antipsychotics $(\mathrm{RR}=1.14 ; 95 \% \mathrm{CI}$ : 1.04-1.25). By contrast, comparing the $\mathrm{RR}$ of the incidence rates of these outcomes during the COVID period, in 2021 vs 2019, we observed a significant increase in the incidence of almost all outcomes, depression $(\mathrm{RR}=1.38 ; 95 \% \mathrm{CI}: 1.27-1.5)$, anxiety $(\mathrm{RR}=1.33 ; 95 \% \mathrm{CI}: 1.25-1.42)$, stress $(\mathrm{RR}=1.2 ; 95 \% \mathrm{CI}: 1.14-1.27)$ and eating disorders $(\mathrm{RR}=1.55 ; 95 \% \mathrm{CI}: 1.39-1.72)$, antidepressants $(\mathrm{RR}=1.27 ; 95 \% \mathrm{CI}: 1.2-1.35)$ and antipsychotics 
medRxiv preprint doi: https://doi.org/10.1101/2022.01.06.22268809; this version posted January 6, 2022. The copyright holder for this preprint (which was not certified by peer review) is the author/funder, who has granted medRxiv a license to display the preprint in perpetuity.

It is made available under a CC-BY-NC-ND 4.0 International license .

$(\mathrm{RR}=1.28 ; 95 \% \mathrm{CI}: 1.18-1.39)$. The exception was a non-significant increase in the dispensation of anxiolytics ( $\mathrm{RR}=1.13$; 95\% CI: 0.99-1.29).

In the gender-stratified analyses, most of the increase in the incidence rates of psychiatric diagnoses and medications was associated with girls, while boys presented risk rates that were not significantly different from previous years (Figure 1A). The incidence rates of antidepressants in girls increased by $42 \%$ during the COVID pandemic vs $14 \%$ in the prepandemic period $(\mathrm{RR}=1.42$; 95\% CI: $1.31-1.53$ vs $\mathrm{RR}=1.14 ; 95 \% \mathrm{CI}: 1.04-1.24$, respectively). The incidence rates of antipsychotics increased by $68 \%$ during COVID vs $15 \%$ before COVID $(\mathrm{RR}=1.68 ; 95 \% \mathrm{CI}: 1.49-1.9$ vs $\mathrm{RR}=1.15 ; 95 \% \mathrm{CI}: 0.99-1.32$, respectively). The RRs during COVID vs pre COVID were significantly higher among girls in all diagnoses that we examined, depression $(\mathrm{RR}=1.68$; 95\% CI: 1.51-1.87 vs $\mathrm{RR}=1.07$; 95\% CI: 0.94-1.21), anxiety $(\mathrm{RR}=1.42$; 95\% CI: 1.3-1.54 vs RR=1.16; 95\% CI: 1.05-1.27), stress (RR=1.29; 95\% CI: 1.2-1.39 vs $\mathrm{RR}=1.03$; 95\% CI: 0.95-1.12) and eating disorders ( $\mathrm{RR}=1.67$; 95\% CI: $1.48-1.88$ vs $\mathrm{RR}=1.06$; 95\% CI: 0.92-1.21). The only significant incidence increase seen in boys was new diagnoses of anxiety (during COVID period $\mathrm{RR}=1.22$; 95\% CI: $1.11-1.35$ vs pre-COVID $\mathrm{RR}=0.95$; 95\% CI: 0.85-1.05).

The sector-stratified analyses showed that most of the increase in the incidence rates of psychiatric diagnoses and medications dispensation was associated with the general Jewish sector, while in the Arab and ultra-orthodox sectors there were no significant increases in incidences of most of the diagnoses and medications dispensation during the COVID-19 pandemic (Figure 1B). The incidence rates of anxiety among ultra-orthodox Jews increased by $28 \%$ during pandemic period (COVID period $\mathrm{RR}=1.28$; 95\% CI: 1.02-1.62 vs pre-COVID $\mathrm{RR}=0.81$; 95\% CI: 0.64-1.04) and among Arabs by 56\% (COVID period RR=1.56; 95\% CI: 1.07-2.27 vs pre-COVID RR=0.81; 95\% CI: 0.61-1.08). 
medRxiv preprint doi: https://doi.org/10.1101/2022.01.06.22268809; this version posted January 6, 2022. The copyright holder for this preprint (which was not certified by peer review) is the author/funder, who has granted medRxiv a license to display the preprint in perpetuity.

It is made available under a CC-BY-NC-ND 4.0 International license.

Table 1 Incidence rates per 1,000 of mental health diagnoses and medication dispensation for 2017, 2019 and 2021 by sex and sector.

\begin{tabular}{|c|c|c|c|c|c|c|c|}
\hline & \multicolumn{3}{|c|}{ Medications } & \multicolumn{4}{|c|}{ Diagnoses } \\
\hline & Antidepressants & Anxiolytics & Antipsychotics & Depression & Anxiety & Stress & $\begin{array}{c}\text { Eating } \\
\text { disorders }\end{array}$ \\
\hline $\begin{array}{l}\text { Population } \\
\text { size }\end{array}$ & \multicolumn{3}{|c|}{ \# of members } & \multicolumn{4}{|c|}{ \# of members } \\
\hline 2017 & 212,163 & 215,824 & 212,741 & 216,121 & 209,208 & 201,670 & 212,104 \\
\hline 2019 & 220,245 & 224,870 & 220,544 & 224,552 & 216,751 & 205,791 & 219,590 \\
\hline 2021 & 231,381 & 237,292 & 231,593 & 236,291 & 227,311 & 212,331 & 230,499 \\
\hline All & \multicolumn{3}{|c|}{ Rates per } & \multicolumn{4}{|c|}{ Rates per 1,000} \\
\hline 2017 & 7.8 & 2.2 & 4.0 & 4.0 & 6.9 & 10.5 & 2.4 \\
\hline 2019 & 8.8 & 1.9 & 4.5 & 4.1 & 7.3 & 10.2 & 2.5 \\
\hline 2021 & 11.1 & 2.1 & 5.8 & 5.7 & 9.7 & 12.2 & 3.9 \\
\hline \multicolumn{8}{|l|}{ Gender } \\
\hline \multicolumn{8}{|l|}{ Male } \\
\hline 2017 & 7.1 & 1.9 & 4.6 & 3.5 & 6.6 & 9.4 & 1.1 \\
\hline 2019 & 7.8 & 1.5 & 5.3 & 3.5 & 6.3 & 8.4 & 1.1 \\
\hline 2021 & 8.5 & 1.7 & 5.2 & 3.4 & 7.7 & 9.0 & 1.3 \\
\hline \multicolumn{8}{|l|}{ Female } \\
\hline 2017 & 8.6 & 2.5 & 3.3 & 4.5 & 7.2 & 11.6 & 3.8 \\
\hline 2019 & 9.8 & 2.3 & 3.8 & 4.8 & 8.3 & 12.0 & 4.0 \\
\hline 2021 & 13.8 & 2.6 & 6.4 & 8.1 & 11.8 & 15.5 & 6.6 \\
\hline \multirow{2}{*}{\multicolumn{8}{|c|}{$\begin{array}{l}\text { Sectors } \\
\text { General } \\
\text { Jewish }\end{array}$}} \\
\hline & & & & & & & \\
\hline 2017 & 8.6 & 2.2 & 3.8 & 4.4 & 7.5 & 11.4 & 2.7 \\
\hline 2019 & 9.5 & 2.0 & 4.3 & 4.6 & 8.2 & 11.1 & 2.8 \\
\hline 2021 & 12.4 & 2.2 & 5.8 & 6.6 & 10.8 & 13.5 & 4.5 \\
\hline \multicolumn{8}{|l|}{ Arab } \\
\hline 2017 & 2.2 & 1.5 & 1.4 & 1.8 & 3.3 & 6.6 & 1.1 \\
\hline 2019 & 2.3 & 1.0 & 1.2 & 1.8 & 2.6 & 5.3 & 0.7 \\
\hline $\begin{array}{l}\text { Ultra- } \\
\text { orthodox } \\
\text { Jewish }\end{array}$ & 2.5 & 1.2 & 2.0 & 1.5 & 4.1 & 5.9 & 1.1 \\
\hline 2017 & 6.5 & 2.1 & 6.9 & 2.5 & 5.5 & 7.2 & 1.4 \\
\hline 2019 & 8.2 & 1.6 & 8.4 & 2.6 & 4.5 & 7.3 & 1.6 \\
\hline 2021 & 7.8 & 1.8 & 8.1 & 2.2 & 5.8 & 8.0 & 1.5 \\
\hline
\end{tabular}


A.
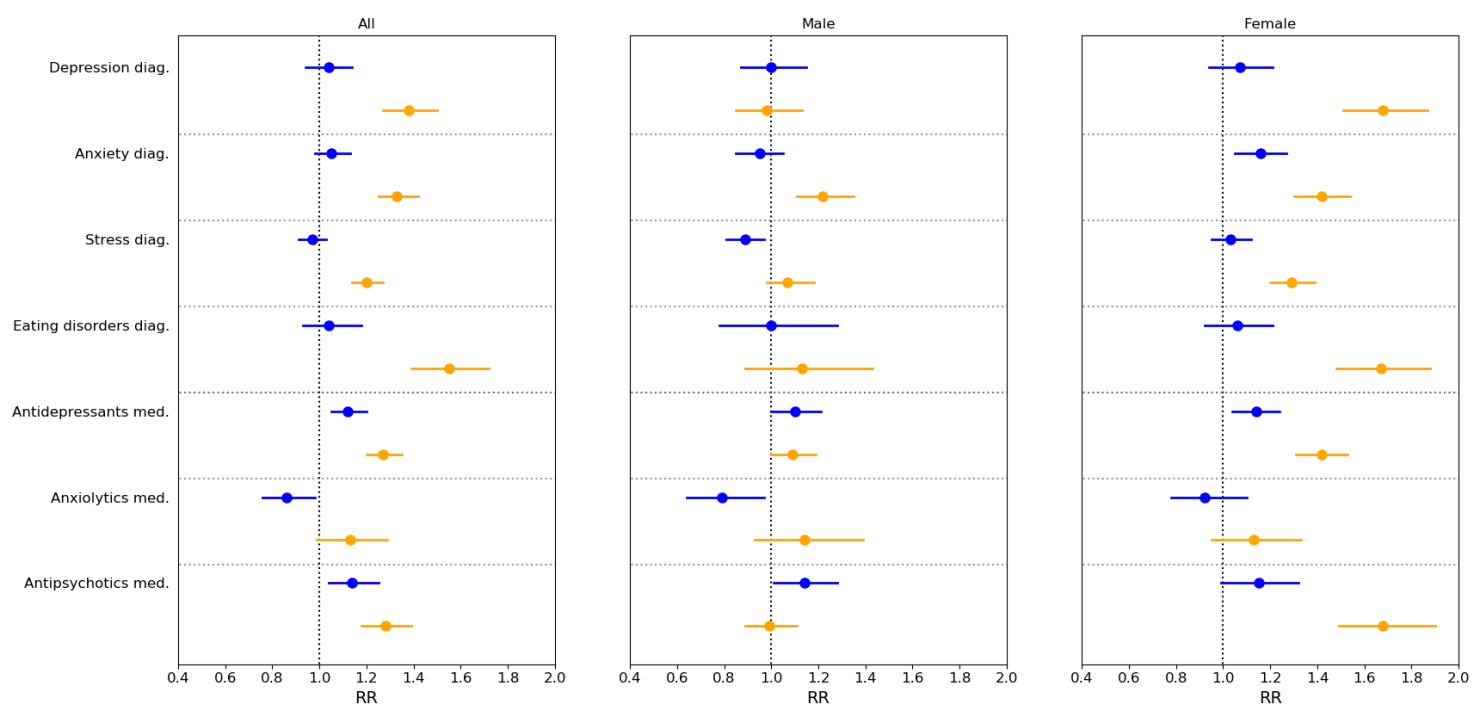

Pre-COVID
COVID

B.
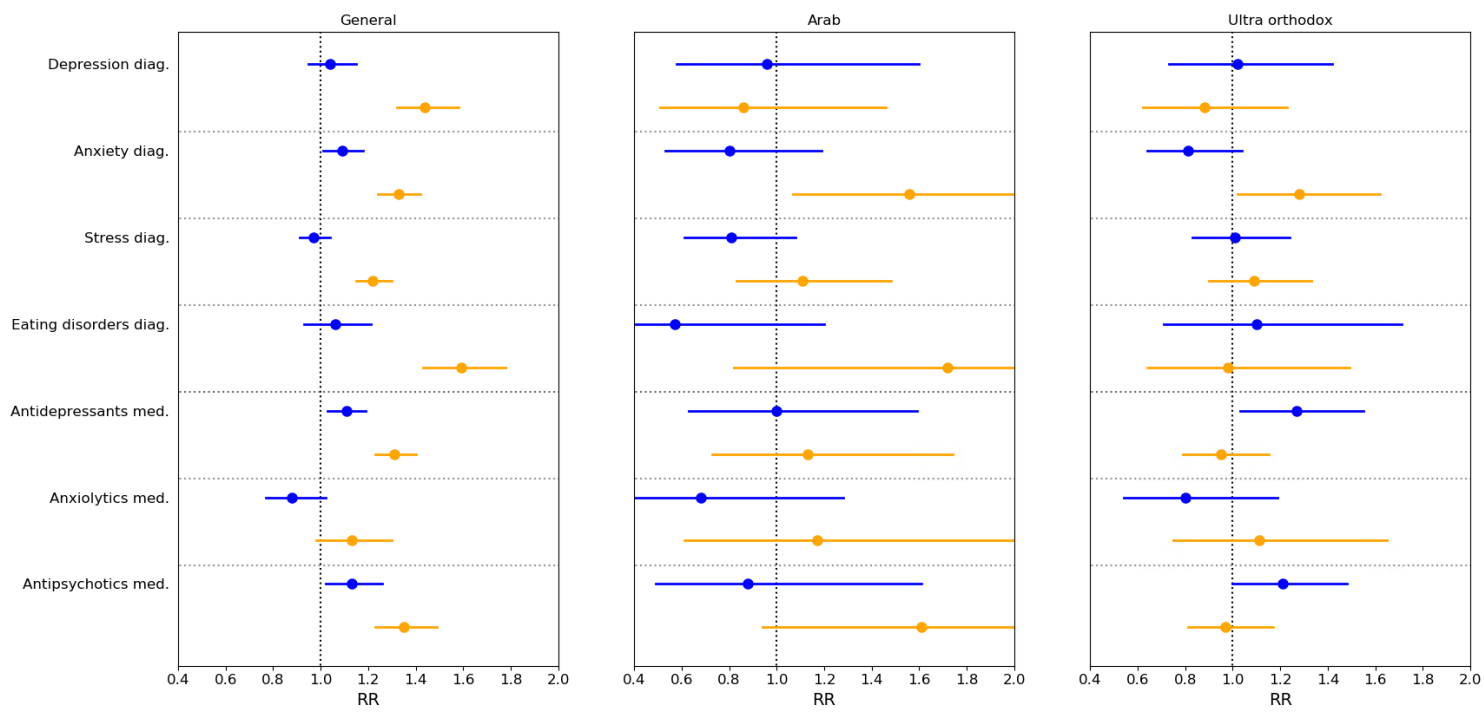

- Pre-covid

Fig. 1 Comparison of risk for incidence of mental health diagnoses and psychiatric drug dispensation by gender (A) and sector (B). Blue circles denote the RR between 2017 and 2019 (pre-COVID). Orange circles denote the RR between 2019 and 2021 (COVID vs. pre COVID). Horizontal (solid) lines denote the 95\% confidence interval for the RR. 
medRxiv preprint doi: https://doi.org/10.1101/2022.01.06.22268809; this version posted January 6, 2022. The copyright holder for this preprint (which was not certified by peer review) is the author/funder, who has granted medRxiv a license to display the preprint in perpetuity.

It is made available under a CC-BY-NC-ND 4.0 International license .

\section{Discussion}

The COVID-19 pandemic has taken a toll on the mental health and wellbeing of children and adolescents. While most recent studies used surveys to obtain current status of mental health in kids ${ }^{6,7}$, we have approached the issue from a quantitative perspective and evaluated psychiatric diagnoses and drug dispensation in adolescents before and during the COVID-19 pandemic. Consistent with studies showing a sharp increase in reports of mental health problems $3,6,8$, we observed a significant increase in diagnosis of depression, anxiety, stress and eating disorders during the COVID-19 era compared to previous years. These observations can be attributed to anything from fear of the new unknown illness to extended lockdowns and school closures causing prolonged social isolation, lack of physical activity and inadequate healthy daily routines 9,10 . Closures and extended contact with the parents at home may also increase parental awareness and there may also be an increase in legitimacy to discuss mental distress during these times ${ }^{11}$.

Our analysis emphasizes the significant higher risk of girls aged 12-17 years suffering a mental disorder for the first time during the pandemic. While this could imply that girls are more sensitive to the effects of the pandemic, this can also be attributed to higher tendency of girls sharing their mental distress with their parents or physicians and getting the diagnosis and treatment for their condition. Indeed, stay-at-home policies and school closures may have given teenagers more opportunity to share such problems with their parents, and for parents to observe such difficulties even if they were not verbally communicated. The lack of increase among boys might be because generally they are more frequently referred to mental health services by their school following behavioral issues. Since schools were closed during large parts of the analyzed period, potential increase due to the pandemic may have been offset by the decrease in school referrals.

Comparing the sectors in the Israeli population interestingly shows that different circumstances and lifestyle during the coronavirus period affect mental health outcomes in adolescents. Ultra-orthodox Jews that were less exposed to the media, were less inclined to close their schools and leaned heavily on their faith and community, did not show the increase in mental health diagnoses and medication dispensation as the general sector did.

While the findings in this report are clear and consistent with other studies, we are aware that they probably under-represent reality. A large population of adolescents is diagnosed and 
medRxiv preprint doi: https://doi.org/10.1101/2022.01.06.22268809; this version posted January 6, 2022. The copyright holder for this preprint (which was not certified by peer review) is the author/funder, who has granted medRxiv a license to display the preprint in perpetuity.

It is made available under a CC-BY-NC-ND 4.0 International license .

treated by mental health professionals in private clinics outside their HMO, and then their diagnoses are not recorded in their EHR. Psychiatric drugs prescribed outside the HMO are also not recorded and were not included in this analysis. Furthermore, mental health services lines are long and on average, adolescents wait 3 months for mental health services, so not all those who seek and need help are included in this study. Our analysis addressed these limitations by comparing the risk ratios of the outcomes, measuring the difference in new mental health diagnoses and dispensation within the HMO in different time periods. Overall, we estimate that there are higher incidence rates than those presented here.

As the fifth coronavirus wave led by the Omicron strain is starting, these results should be considered when deciding on policies for containing it. Our findings highlight that together with the risk of a new strain infecting the population, attention should be given to the mental health of adolescents - especially secular girls - and measures to safeguard their mental health and wellbeing should be weighed.

\section{Funding}

No external funding was used for this study

\section{Conflict of Interest}

The authors declare they have no conflict of interest

\section{Data sharing statement}

Due to data privacy regulations, the raw data used in this study cannot be shared publicly.

\section{References}

1. Zimmermann, P. \& Curtis, N. Why is COVID-19 less severe in children? A review of the proposed mechanisms underlying the age-related difference in severity of SARS-CoV-2 infections. Archives of Disease in Childhood 106, 429-439 (2021).

2. Howard-Jones, A. R. et al. COVID-19 in children: I. Epidemiology, prevention and indirect impacts. Journal of Paediatrics and Child Health n/a,. 
medRxiv preprint doi: https://doi.org/10.1101/2022.01.06.22268809; this version posted January 6, 2022. The copyright holder for this preprint (which was not certified by peer review) is the author/funder, who has granted medRxiv a license to display the preprint in perpetuity.

It is made available under a CC-BY-NC-ND 4.0 International license .

3. Magson, N. R. et al. Risk and Protective Factors for Prospective Changes in Adolescent Mental Health during the COVID-19 Pandemic. J Youth Adolescence 50, 44-57 (2021).

4. Meherali, S. et al. Mental Health of Children and Adolescents Amidst COVID-19 and Past Pandemics: A Rapid Systematic Review. International Journal of Environmental Research and Public Health 18, 3432 (2021).

5. Thorisdottir, I. E. et al. Depressive symptoms, mental wellbeing, and substance use among adolescents before and during the COVID-19 pandemic in Iceland: a longitudinal, population-based study. The Lancet Psychiatry 8, 663-672 (2021).

6. Racine, N. et al. Global Prevalence of Depressive and Anxiety Symptoms in Children and Adolescents During COVID-19: A Meta-analysis. JAMA Pediatrics (2021) doi:10.1001/jamapediatrics.2021.2482.

7. Listernick, Z. I. \& Badawy, S. M. Mental Health Implications of the COVID-19 Pandemic Among Children and Adolescents: What Do We Know so Far? PHMT Volume 12, 543-549 (2021).

8. Cost, K. T. et al. Mostly worse, occasionally better: impact of COVID-19 pandemic on the mental health of Canadian children and adolescents. Eur Child Adolesc Psychiatry (2021) doi:10.1007/s00787-021-01744-3.

9. Fegert, J. M., Vitiello, B., Plener, P. L. \& Clemens, V. Challenges and burden of the Coronavirus 2019 (COVID-19) pandemic for child and adolescent mental health: a narrative review to highlight clinical and research needs in the acute phase and the long return to normality. Child Adolesc Psychiatry Ment Health 14, 20 (2020).

10. Camila Saggioro de Figueiredo. COVID-19 pandemic impact on children and adolescents' mental health: Biological, environmental, and social factors. (2021). 
medRxiv preprint doi: https://doi.org/10.1101/2022.01.06.22268809; this version posted January 6, 2022. The copyright holder for this preprint (which was not certified by peer review) is the author/funder, who has granted medRxiv a license to display the preprint in perpetuity. It is made available under a CC-BY-NC-ND 4.0 International license.

11. Rider, E. A., Ansari, E., Varrin, P. H. \& Sparrow, J. Mental health and wellbeing of children and adolescents during the covid-19 pandemic. $B M J 374, \mathrm{n} 1730$ (2021). 